\title{
Toxic elements and bio-metals in Cantharellus mushrooms from Poland and China
}

\author{
Jerzy Falandysz ${ }^{1}$ (D) Maria Chudzińska ${ }^{2,3}$ - Danuta Barałkiewicz ${ }^{2}$. \\ Malgorzata Drewnowska $^{1}$ - Anetta Hanć ${ }^{2}$
}

Received: 3 December 2016 / Accepted: 2 February 2017 /Published online: 18 March 2017

(C) The Author(s) 2017. This article is published with open access at Springerlink.com

\begin{abstract}
Data on multi-trace element composition and content relationships have been obtained for Cantharellus cibarius, C. tubaeformis, and C. minor mushrooms from Poland and China by inductive coupled plasma-dynamic reaction cell-mass spectroscopy. There is no previous data published on $\mathrm{As}, \mathrm{Li}, \mathrm{V}, \mathrm{Tl}$, and $\mathrm{U}$ in chanterelles from Poland and on $\mathrm{Ba}, \mathrm{Co}, \mathrm{Cr}, \mathrm{Ni}, \mathrm{Rb}$, and $\mathrm{Sr}$ in chanterelles from China. The results implied a role of the soil background geochemistry at the collection site with the occurrence of $\mathrm{Ag}, \mathrm{As}, \mathrm{Ba}, \mathrm{Cr}, \mathrm{Cs}$, $\mathrm{Li}, \mathrm{Mn}, \mathrm{Pb}, \mathrm{Rb}, \mathrm{Sr}, \mathrm{U}$, and $\mathrm{V}$ in the fruiting bodies. Both geogenic $\mathrm{Cd}$ and anthropogenic $\mathrm{Cd}$ can contribute in load of this element in chanterelles from the Świetokrzyskie Mts. region in Poland, while geogenic source can be highly dominant in the background areas of Yunnan. An essentiality of $\mathrm{Cu}$ and $\mathrm{Zn}$ and effort by mushroom to maintain their physiological regulation could be reflected by data for Cantharellus mushrooms from both regions of the world, but its geogenic source (and possibly anthropogenic) can matter also in the region of the Świetokrzyskie Mountains in Poland. The elements Co, $\mathrm{Ni}$, and $\mathrm{Tl}$ were at the same order of magnitude in contents in C. cibarius in Poland and Yunnan, China. C. tubaeformis
\end{abstract}

Responsible editor: Philippe Garrigues

Jerzy Falandysz

jerzy.falandysz@ug.edu.pl

1 Laboratory of Environmental Chemistry and Ecotoxicology, Gdańsk University, 63 Wita Stwosza Str, 80-308 Gdańsk, PL, Poland

2 Department of Trace Element Analysis by Spectroscopy Method, Adam Mickiewicz University, Umultowska 89b, 61-614 Poznań, Poland

3 Rozany Strumien Base Station of Integrated Monitoring of Natural Environment, Faculty of Geographical and Geological Sciences, ul. Bogumiła Krygowskiego 10, 61-680 Poznań, Poland differed from $C$. cibarius by a lower content of correlated $\mathrm{Co}, \mathrm{Ni}$, and $\mathrm{Zn}$. Soil which is polymetallic and highly weathered in Yunnan can be suggested as a natural geogenic source of greater concentrations of $\mathrm{As}, \mathrm{Ba}, \mathrm{Cr}, \mathrm{Li}, \mathrm{Pb}, \mathrm{Sr}, \mathrm{U}$, and $\mathrm{V}$ in the chanterelles there while lower of $\mathrm{Mn}$ and $\mathrm{Rb}$, when related to chanterelles in Poland. A difference in Cs content between the sites can be attributed as an effect of the ${ }^{137} \mathrm{Cs}$ release from the Chernobyl accident, in which Poland was much more affected than Yunnan, where deposition was negligible.

Keywords Mushrooms $\cdot$ Minerals $\cdot$ Organic food $\cdot$ Trace elements $\cdot$ China $\cdot$ Poland

\section{Introduction}

Mushrooms from the genus Cantharellus are well recognizable and are a popular food item in many regions of the world, e.g., C. cibarius Fr. The common names for $C$. cibarius are chanterelle, common chanterelle, golden chanterelle, or girolle. Advances in analytical methods and instrumentation enabled in recent years better insight into the mineral constituents of mushrooms (Dimitrijevic et al. 2016; Gąsecka et al. 2017; Mleczek et al. 2017; Stefanović et al. 2016a, b).

Wild-growing mushrooms are valued ingredients of food or special dishes in the tradition of many people around the world. Documented data indicate that intake of wild-growing mushrooms could exceed $20 \mathrm{~kg}$ of fresh product per capita annually in Yunnan province, China, and also in a rural region of the UK (Barret et al. 1999; Zhang et al. 2010). Hence, wildgrowing mushrooms without doubt are important organic food items in the diet of many people, while our knowledge on their mineral constituent composition and content, and their fate during culinary processing and their accessibility, has many gaps. In a study of wild-growing mushrooms, it is 
also important to better understand their mineral constituent composition in the context of the best analytical chemistry, the natural geochemistry of the soil substratum where the mycelium grows as well as the physiology of a species (Aloupi et al. 2011; Falandysz et al. 2012a, b; Kojta and Falandysz 2016; Kojta et al. 2015; Kubrová and Borovička 2015; Mleczek et al. 2016; Nearing et al. 2014; Tel et al. 2014). This study aimed to update information on the content of some essential and hazardous metallic elements accumulated in Cantharellus mushrooms foraged in Poland and China as determined by inductively coupled plasma mass spectroscopy with a dynamic reaction cell (ICP-DRC-MS). Available data on the baseline content of the geogenic metallic elements and metalloids in soils from the background areas in Yunnan as well as a geogenic and anthropogenic sources in Poland can explain results obtained for chanterelle mushrooms.

\section{Materials and methods}

\section{Mushrooms}

Ten composite samples of fruiting bodies of the mushroom C. cibarius Fr. were collected from the following sites: Jastrzebia Góra (CC-1), Darżlubska (CC-2), Kościerzyna forests (CC-3), Tuchola Pinewoods-Osiek (CC-4), and Tuchola Pinewoods (CC-5) in the Pomerania region; Ciechocinek
$(\mathrm{CC}-7)$ in the Kujawy region; Poznań outskirts (CC-8) in Great Poland Voivodship; Bobrowniki (CC-6) in the Podlasie region; Pieszków (CC-10) in the Świętokrzyskie region; and Głogów Małopolski (CC-11) in Little Poland Voivodship of Poland in 2012-2014; one shipment was bought in a shop in Poland (CC-9) and another one was collected from the region of Yuxi county $(\mathrm{CC}-12)$ in the province of Yunnan in China in 2013. C. minor Peck was collected from Yuxi (CM-1) during 2013 and C. tubaeformis (Fr.) Quél from two locations: Mojusz (CT-1) and Kartuzy (CT-2) in Pomerania, Poland, were collected in 2007-2008 (Fig. 1 and Table 2).

Fresh mushrooms were immediately cleaned from any visible plant vegetation and soil debris with a plastic knife and further rinsed with deionized water, and the bottom part of the stem was cut off. Subsequently, the mushroom samples were placed into plastic trays of an electrically heated commercial dryer (dehydrator for mushrooms, fruits, vegetables, and herbs; model MSG-01; MPM Product, Milanówek, Poland, and Ultra FD1000 dehydrator, Ezidri, Australia) and dried at $65{ }^{\circ} \mathrm{C}$ to constant mass. Dried fungal materials were pulverized in a porcelain mortar that was cleaned by hand washing using a laboratory brush, deionized water, and detergent and then further rinsed with distilled water and dried in an electrically heated laboratory dryer at $105{ }^{\circ} \mathrm{C}$. Pulverized mushrooms were kept in brand new sealed polyethylene bags under dry conditions.

Fig. 1 Localization of the sampling places of the Cantharellus mushrooms in Poland and China (see Table 2)

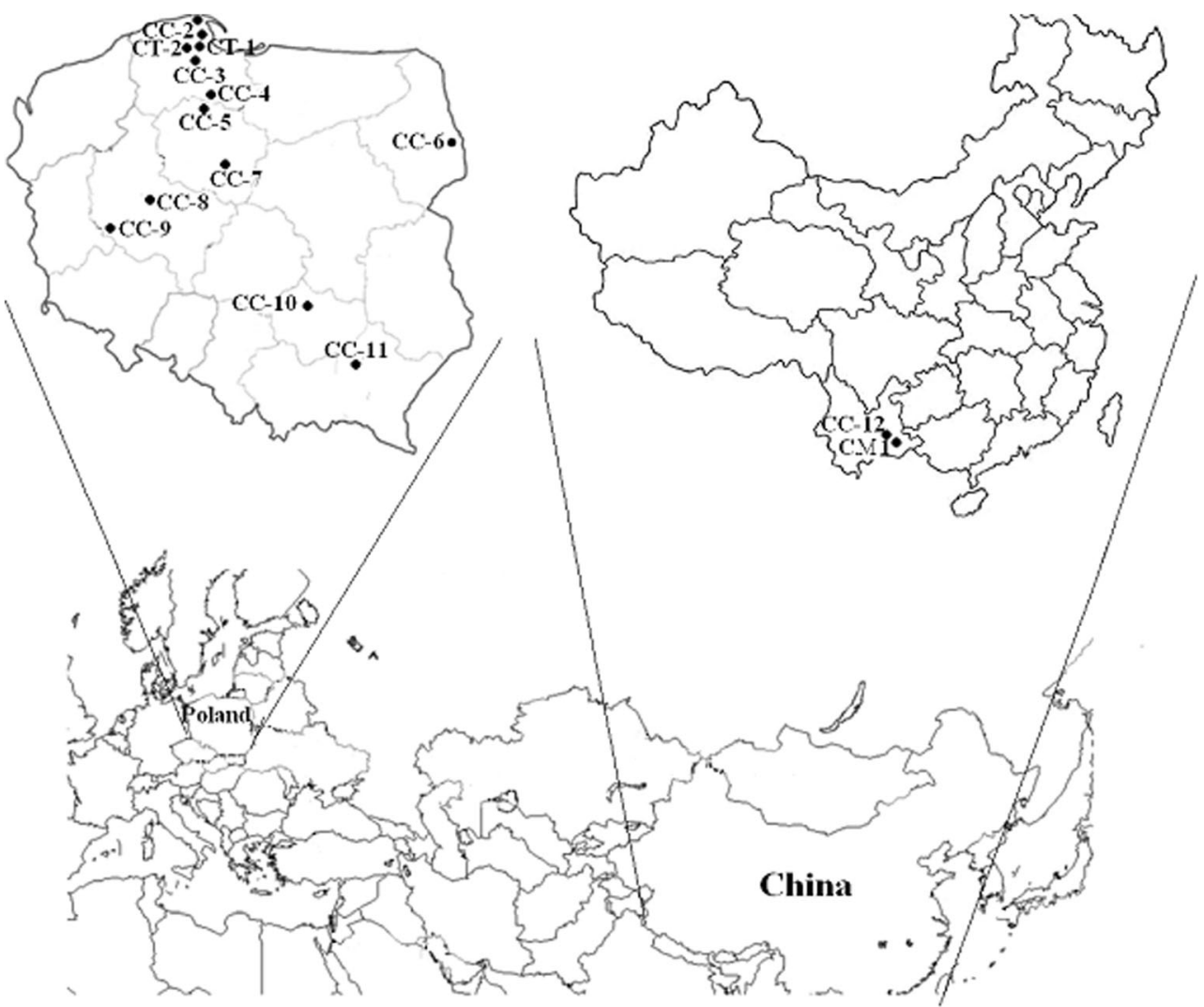




\section{Elemental analysis}

Before digestion, the samples were dried in $65^{\circ} \mathrm{C}$ for $12 \mathrm{~h}$ using an electrically heated laboratory oven. Then, subsamples of dried and powdered mushrooms ( 0.5000 g) were digested with $5 \mathrm{~mL}$ of $65 \% \mathrm{HNO}_{3}$ (Suprapure, Merck, Germany) under pressure in a model Ethos One (Milestone Srl, Italy) microwave oven. The rotor body holds up to ten digestion vessels made of high-purity TFMTM polytetrafluoroethylene (PTFE) with capacity of 50-mL per vessel. The heating program was performed in one step: the power of the process was $1500 \mathrm{~W}$, ramp time $20 \mathrm{~min}$, temperature $200{ }^{\circ} \mathrm{C}$, and hold time $30 \mathrm{~min}$. Blank reagent solutions were prepared in the same way. For every set of ten digested mushroom samples, two blank samples were run. The digests were diluted to $10 \mathrm{~mL}$ using deionized water (TKA Smart2Pure, Niederelbert, Germany) in volumetric flasks. If this was necessary, a specific digest was further diluted (about ten times) to keep a linearity of measurements or acid concentration below $3 \%$.

\section{Instrumentation}

Elemental analysis of the elements (Ag, As, Ba, Cd, Co, Cs, $\mathrm{Cu}, \mathrm{Cr}, \mathrm{Li}, \mathrm{Mn}, \mathrm{Ni}, \mathrm{Pb}, \mathrm{Rb}, \mathrm{Sr}, \mathrm{V}, \mathrm{Tl}, \mathrm{U}$, and $\mathrm{Zn}$ ) was carried out using the ELAN DRC II ICP-MS Inductively Coupled Plasma Mass Spectrometer (PerkinElmer, SCIEX, Canada) equipped with a Meinhard concentric nebulizer, cyclonic spray chamber, dynamic reaction cell, Pt cones, and quadruple mass analyzer. For dynamic reactive cell (DRC), as reaction gas, ammonia (99.999\% purity ammonia, Linde Gas, Kraków, Poland) to eliminate possible spectral interferences in determination of $\mathrm{Cr}, \mathrm{Mn}, \mathrm{V}$, and $\mathrm{Zn}$ ) and oxygen (99.999\% purity oxygen, Linde Gas, Kraków, Poland) were used for free from spectral interferences determination of As.

The ICP-MS was run at the following conditions: RF power- $1100 \mathrm{~W}$; plasma Ar flow rate- $15 \mathrm{~L} \mathrm{~min}^{-1}$; nebulizer Ar flow rate $-0.87 \mathrm{~L} \mathrm{~min}^{-1}$ and auxiliary Ar flow rate- $1.2 \mathrm{~L}$ $\min ^{-1}$; and lens voltage-(7.5-9.0) V. A mixed standard solution with contents of $10 \mathrm{mg} \mathrm{L}^{-1}$ was used (Multielement Calibration Standard 3, Atomic Spectroscopy Standard, PerkinElmer Pure). Moreover, the isotopes of ${ }^{45} \mathrm{Sc},{ }^{74} \mathrm{Ge}$, ${ }^{103} \mathrm{Rh}$, and ${ }^{159} \mathrm{~Tb}$ prepared from individual solutions with contents of $1000 \mathrm{mg} \mathrm{L}^{-1}$ were applied as internal standards in order to effectively correct temporal variations in signal intensity (ICP Standard CertiPUR, Merck, Germany).

Generally, calibration curves for elements were prepared in the range of 0.1 to $50 \mu \mathrm{g} \mathrm{L}^{-1}$. Argon $(99.999 \%)$ was used as a nebulizer, auxiliary, and plasma gas (Messer, Chorzów, Poland). If concentration of an element measured in a digest exceeded the maximum value for the calibration curve, a digest was diluted respectively and re-examined. All absolute values of the element contents determined and presented for the Chanterelle mushrooms are given in $\mathrm{mg} \mathrm{kg}^{-1}$ dry biomass $(\mathrm{db})$.

\section{Quality control/quality assurance}

The methods of trace element measurement were validated and controlled by preparation of standard solutions; calibration of instruments; and daily runs of blank samples, duplicates, and replicates with each analytical cycle. All samples were analyzed in batches with certified reference materials and blanks. Duplicates and blanks were measured with every set of ten mushroom samples. Evaluation of the accuracy of the analytical method was based on analysis of the two certified reference materials (CRM): mushroom powder IC-CSM-4, Institute of Nuclear Technology and Chemistry in Warsaw, ICHTJ, Poland, and Oriental Basma Tobacco Leaves, INCT-OBTL-5, Institute of Nuclear Technology and Chemistry in Warsaw, ICHTJ, Poland (Table 1). Precision was calculated as the coefficient of variations (CV) of duplicates. As a result of the analysis, the following measurement precision values were in the range from 1 to $8 \%$ for all investigated elements. Finally, the limits of detection, calculated as three standard deviations of seven independent replicates of the reagent blank, were respectively (in $\mu \mathrm{g} \mathrm{L}^{-1}$ ) 0.003 for $\mathrm{Ag}$, 0.03 for As, 0.2 for $\mathrm{Ba}, 0.008$ for $\mathrm{Cd}, 0.001$ for $\mathrm{Co}, 0.2$ for $\mathrm{Cr}, 0.01$ for $\mathrm{Cs}, 0.15$ for $\mathrm{Cu}, 0.02$ for $\mathrm{Li}, 0.4$ for $\mathrm{Mn}, 0.05$ for $\mathrm{Ni}, 0.07$ for $\mathrm{Pb}, 0.03$ for $\mathrm{Rb}, 0.06$ for $\mathrm{Sr}, 0.001$ for $\mathrm{Tl}, 0.004$ for $\mathrm{U}, 0.09$ for $\mathrm{V}$; and 4 for $\mathrm{Zn}$.

\section{Statistical analyses}

The computer software Statistica, version 10.0 (Statsoft Polska, Kraków, Poland), was used for statistical analysis of data and for graphical presentation of the results of twodimensional multiple scatter plot relationships between the variables.

\section{Results and discussion}

\section{$\mathrm{Cu}, \mathrm{Mn}$, and $\mathrm{Zn}$}

Copper, manganese, and zinc are essential elements both for fungi and humans. For $C$. cibarius in Poland, the element $\mathrm{Cu}$ ranged from 34 up to $53 \mathrm{mg} \mathrm{kg}^{-1} \mathrm{db}$ in the Świętokrzyskie Mountain region of Piekoszów, while being lower in Yunnan, i.e., at $31 \mathrm{mg} \mathrm{kg}^{-1} \mathrm{db}$. C. minor from Yunnan showed the lowest content in this study, i.e., $27 \mathrm{mg} \mathrm{kg}^{-1} \mathrm{db}$. The Świętokrzyskie Mts. region in the south-central Poland is an area where copper was mined in the past for almost six centuries in some places, and soil background there can be enriched in $\mathrm{Cu}$ and also $\mathrm{Cr}, \mathrm{Mn}, \mathrm{Ni}, \mathrm{Zn}, \mathrm{As}, \mathrm{Cd}, \mathrm{Pb}$, and $\mathrm{U}$ 
Table 1 Results of the measurements of accuracy of the analytical data using certificate reference materials "fungal powdered fruiting bodies of Leccinum scabrum" IC-CS-M-4 $(n=5)$ and Oriental basma tobacco leaves, INCT-OBTL-5 $(n=5)$

\begin{tabular}{lllr}
\hline Analyte & Measured value $\left(\mathrm{mg} \mathrm{kg}^{-1}\right)$ & Certified value $\left(\mathrm{mg} \mathrm{kg}^{-1}\right)$ & Recovery $(\%)$ \\
\hline $\mathrm{Ag}^{\mathrm{b}}$ & $0.062 \pm 0.003$ & $0.053 \pm 0.011$ & 116 \\
$\mathrm{As}^{\mathrm{a}}$ & $0.416 \pm 0.018$ & $0.375 \pm 0.051$ & 111 \\
$\mathrm{Ba}^{\mathrm{b}}$ & $63.2 \pm 2.2$ & $67.4 \pm 3.8$ & 94 \\
$\mathrm{Cd}^{\mathrm{a}}$ & $1.43 \pm 0.13$ & $1.33 \pm 0.09$ & 107 \\
$\mathrm{Co}^{\mathrm{b}}$ & $0.949 \pm 0.043$ & $0.981 \pm 0.067$ & 97 \\
$\mathrm{Cr}^{\mathrm{a}}$ & $1.05 \pm 0.11$ & $1.09 \pm 0.21$ & 96 \\
$\mathrm{Cs}^{\mathrm{b}}$ & $0.261 \pm 0.01$ & $0.288 \pm 0.02$ & 91 \\
$\mathrm{Cu}^{\mathrm{a}}$ & $28.18 \pm 0.98$ & $26.37 \pm 1.74$ & 107 \\
$\mathrm{Li}^{\mathrm{b}}$ & $18.8 \pm 0.65$ & $19.3^{\mathrm{c}}$ & 97 \\
$\mathrm{Mn}^{\mathrm{b}}$ & $174 \pm 5$ & $180 \pm 6$ & 97 \\
$\mathrm{Ni}^{\mathrm{b}}$ & $8.94 \pm 0.49$ & $8.5 \pm 0.49$ & 105 \\
$\mathrm{~Pb}^{\mathrm{a}}$ & $1.032 \pm 0.06$ & $0.998 \pm 0.072$ & 103 \\
$\mathrm{Rb}^{\mathrm{b}}$ & $18.5 \pm 0.6$ & $19.1 \pm 1$ & 97 \\
$\mathrm{Sr}^{\mathrm{b}}$ & $101 \pm 1$ & $105 \pm 5$ & 96 \\
$\mathrm{Tl}^{\mathrm{b}}$ & $0.044 \pm 0.001$ & $0.051^{\mathrm{c}}$ & 86 \\
$\mathrm{U}^{\mathrm{b}}$ & $0.100 \pm 0.002$ & $0.113^{\mathrm{c}}$ & 88 \\
$\mathrm{~V}^{\mathrm{b}}$ & $3.98 \pm 0.10$ & $4.12 \pm 0.55$ & 97 \\
$\mathrm{Zn}^{\mathrm{a}}$ & $127.8 \pm 5.2$ & $120.7 \pm 5.9$ & 106 \\
\hline
\end{tabular}

${ }^{\mathrm{a}} \mathrm{IC}-\mathrm{CS}-\mathrm{M}-4$

${ }^{\mathrm{b}}$ INCT-OBTL-5; ${ }^{\mathrm{c}}$ Information values

${ }^{\mathrm{c}}$ Information values
(Gałuszka et al. 2015). Hence, a maximum content of $\mathrm{Cu}$ determined in C. cibarius from the forests in the region of the Świetokrzyskie Mts. can be explained largely by anomalous geochemistry of soil there. Copper as many other metallic elements is also transported from the anthropogenic sources of emission to more or less remote areas with moving air masses, but they are largely deposited locally (Nygård et al. 2012; Steinnes and Friedland 2006). Airborne heavy metals and metalloids when deposited can be retained in soil by adsorption and/or precipitation reactions and not readily available for mushrooms. Airborne deposition of some heavy metals $(\mathrm{Zn}$, $\mathrm{Pb}, \mathrm{Ni}, \mathrm{Cd})$, as it was measured in the organic $(\mathrm{O})$ and mineral (B) layers of the forest soils, was in the past low in the region of the Świętokrzyskie Mts. (Andersen et al. 1994). Also, airborne heavy metal deposition ( $\mathrm{Pb}$ and $\mathrm{As}$ as the tracers) in the region of northwestern Poland was low in the most recent study (Steinnes and Twardowska 2016).

Two sets of $C$. tubaeformis from Poland were similarly high in $\mathrm{Cu}$ with 35 to $39 \mathrm{mg} \mathrm{kg}^{-1} \mathrm{db}$ (Table 2). The absolute values of $\mathrm{Cu}$ in Cantharellus spp. in this study differed between the sites, while contents were in a narrow range in spite of the geographically scattered origin of mushrooms. The data obtained for $\mathrm{Cu}$ for three Cantharellus species agree well with most results available for $C$. cibarius from the different regions of Europe, i.e., they were at $8.2 \pm 1.9$ (this result was considered as outlier); $26 ; 30 \pm 3 ; 32 \pm 0 ; 35 ; 35 ; 37,38$, $39 \pm 2 ; 35 \pm 8$ to $49 \pm 4 ; 42 ; 46 \pm 27 ; 50 ; 52 \pm 8$ to $58 \mathrm{mg} \mathrm{kg}^{-1}$ $\mathrm{db}$, and it was $90 \pm 5 \mathrm{mg} \mathrm{kg}^{-1} \mathrm{db}$ in Turkey, $73 \mathrm{mg} \mathrm{kg}^{-1} \mathrm{db}$ in Mexico, and $24 \pm 0 \mathrm{mg} \mathrm{kg}^{-1} \mathrm{db}$ (only three samples) in USA - as was reviewed recently (Drewnowska and Falandysz 2015; Falandysz and Drewnowska 2015).

Mushrooms vary in $\mathrm{Cu}$ content sequestered in fruiting bodies because of species-specific requirements, while geochemistry of the soil substratum or anthropogenic pollution may also be factors, which could cause a deficit or surplus of the element (Falandysz et al. 2001; Jorhem and Sundström 1995; Mleczek et al. 2015). A previous study showed that soil substratum geochemistry could have an impact on the quantity of $\mathrm{Cu}$ sequestered by $C$. cibarius in fruiting bodies; e.g., individuals from the Baltic Sea coastal area with sandy soil bedrock at the Hel Peninsula in Poland contained this metal at $30 \pm 3 \mathrm{mg} \mathrm{kg}^{-1} \mathrm{db}$, while mushrooms from a region richer in $\mathrm{Cu}$, the montane soils near the town of Zakopane in the Tatra Mts., contained $\mathrm{Cu}$ at $52 \pm 8 \mathrm{mg} \mathrm{kg}^{-1} \mathrm{db}$ (Falandysz et al. 2012a). C. cibarius was able to absorb $\mathrm{Cu}$ more efficiently from the soil substratum poorer in this element (Falandysz and Drewnowska 2015). For soil substrata from background areas unpolluted with $\mathrm{Cu}$, as this was the case in this study, the fruit bodies of $C$. cibarius showed to some degree physiological regulation in a sequestration of the element into the fruiting bodies.

The content of $\mathrm{Mn}$ in the Cantharellus mushrooms was at $19 \pm 1$ to $51 \pm 2 \mathrm{mg} \mathrm{kg}^{-1} \mathrm{db}$ in C. cibarius from Poland and at 


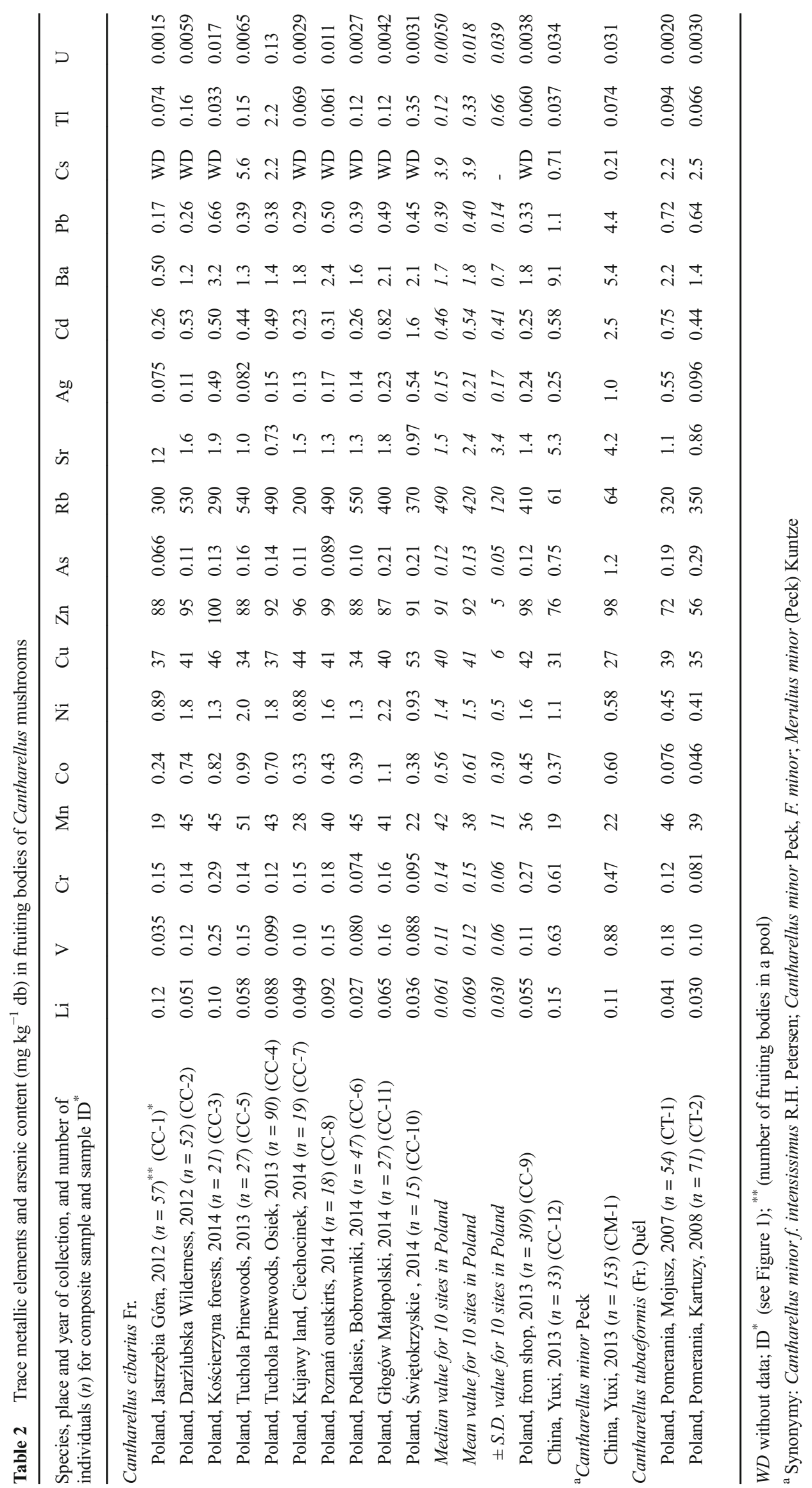


$19 \mathrm{mg} \mathrm{kg}^{-1} \mathrm{db}$ in fruit bodies from Yunnan, at $22 \mathrm{mg} \mathrm{kg}^{-1} \mathrm{db}$ in C. minor, and at 39 to $46 \mathrm{mg} \mathrm{kg}^{-1} \mathrm{db}$ in C. tubaeformis. Cantharellus cibarius from the Baltic Sea coastal place near the location of Jastrzębia Góra contained Mn at 19 and $21 \pm 5 \mathrm{mg} \mathrm{kg}^{-1} \mathrm{db}$ - similar to fruit bodies from a nearby costal location at the Hel Peninsula that showed $21 \pm 5 \mathrm{mg} \mathrm{kg}^{-1}$ db (Falandysz et al. 2012a). Both results suggest on a poor status of Mn in soils at the site of Jastrzębia Góra (for the Hel site Mn was at $2.3 \pm 0.2 \mathrm{mg} \mathrm{kg}^{-1}$ dry matter) (Falandysz et al. 2012a). Manganese in C. cibarius and C. minor from Yunnan was within the lower range of the contents reported internationally for C. cibarius (Falandysz and Drewnowska 2015). Manganese, like some other essential mineral constituents in mushrooms, undergoes physiological regulation, and the lower values reported for Yunnan and two locations in Poland (the coastal and an upland-Ś Swiętokrzyskie mountains) can imply an insufficient supply of the element from the soil substrate.

Zinc in C. cibarius foraged in Poland was at very similar contents for the sites, i.e., at 88 to $100 \mathrm{mg} \mathrm{kg}^{-1} \mathrm{db}$ and at $76 \mathrm{mg} \mathrm{kg}^{-1} \mathrm{db}$ for Yunnan. In C. minor, $\mathrm{Zn}$ was at $98 \mathrm{mg} \mathrm{kg}^{-1}$ $\mathrm{db}$ and in C. tubaeformis at 56 to $72 \mathrm{mg} \mathrm{kg}^{-1} \mathrm{db}$. Those values on $\mathrm{Zn}$ contents are in the central to upper range of the literature values reported for $C$. cibarius (Falandysz and Drewnowska 2015).

\section{$\mathrm{Co}, \mathrm{Cr}$, and $\mathrm{Li}$}

Cobalt, chromium, and lithium are considered as minor trace elements in mushrooms ( ̌̌anda and Kučera 2004; Vetter 2005). The examined $C$. tubaeformis contained cobalt at 0.046 to $0.076 \mathrm{mg} \mathrm{kg}^{-1} \mathrm{db}$. Cobalt in $C$. minor and C. cibarius was at an order of magnitude greater than in C. tubaeformis, i.e., at 0.24 to $1.1 \mathrm{mg} \mathrm{kg}^{-1} \mathrm{db}$ (Table 2); those values agree well with data reported for $C$. cibarius foraged in Poland and examined by ICP-optical emission spectroscopy (OES) (Falandysz and Drewnowska 2015).

C. cibarius and $C$. minor from Yunnan had chromium at 0.47 to $0.61 \mathrm{mg} \mathrm{kg}^{-1} \mathrm{db}$ and were richer $(p<0.05)$ in this element than were $C$. cibarius and $C$. tubaeformis from Poland, which contained it at 0.074 to $0.29 \mathrm{mg} \mathrm{kg}^{-1} \mathrm{db}$ (Table 2). This could be explained by the specific geochemistry of soils in Yunnan, where bedrock in the Circum-Pacific mercuriferous belt is polymetallic and enriched in $\mathrm{Cr}$ (Fan 1991).

Chromium, because of the spectral interferences from other ions, which are formed in a stream of atomized ions in the airacetylene flame or an argon plasma, is difficult or impossible to determine credibly as trace element in biological matrices like mushrooms by flame atomic absorption spectroscopy (FAAS), ICP-OES, or ICP-MS without a dynamic reaction cell. This could have caused doubtful results published on $\mathrm{Cr}$ in mushrooms in the past. The use of a dynamic reaction cell overcomes this problem. The results on chromium in
C. cibarius and C. tubaeformis foraged in Poland, when determined by ICP-MS using a dynamic reaction cell, are within range of data for this element in C. cibarius at $0.14 \pm 0.02$ to $0.16 \pm 0.03 \mathrm{mg} \mathrm{kg}^{-1} \mathrm{db}$ when determined by ICP-OES (Falandysz and Drewnowska 2015).

There is a scarcity of data on lithium in mushrooms. In a study by Vetter (2005), the content of $\mathrm{Li}$ in mushrooms in Hungary was well below $1.0 \mathrm{mg} \mathrm{kg}^{-1} \mathrm{db}$. Also, Sarcodon imbricatus (L.) P. Karst. sampled in Poland contained only a small amount of Li, i.e., at $0.016 \pm 0.004$ in caps and at $0.054 \pm 0.035 \mathrm{mg} \mathrm{kg}^{-1} \mathrm{db}$ in stems (Mędyk et al. 2017).

There is no previous analytical information on $\mathrm{Li}$ in C. cibarius, $C$. tubaeformis, and $C$. minor. The range for $\mathrm{Li}$ in C. cibarius from Poland was from 0.027 to $0.12 \mathrm{mg} \mathrm{kg}^{-1} \mathrm{db}$, and those data confirm the suggestion that mushrooms foraged in Europe are poor in this element. The result for a sole composite sample of the Yunnan's $C$. cibarius is at $0.15 \mathrm{mg} \mathrm{kg}^{-1} \mathrm{db}$ of Li, which is roughly threefold greater than the median value of $0.059 \mathrm{mg} \mathrm{kg}^{-1} \mathrm{db}$ for individuals from Poland.

An examination by Yin et al. of some mushrooms foraged in the northern and northwestern regions of Yunnan showed lithium at $\sim 20$ - to $\sim 100$-fold greater contents than in the mushrooms in this study (Yin et al. 2012). A sample of C. minor Peck, from the Dayao county in Yunnan, showed lithium at $2.6 \mathrm{mg} \mathrm{kg}^{-1} \mathrm{db}$. Some other mushrooms foraged showed lithium at $>1 \mathrm{mg} \mathrm{kg}^{-1}$ $\mathrm{db}$ : for example, in Thelephora vialis Schwein., it was $12 \mathrm{mg}$ $\mathrm{kg}^{-1} \mathrm{db}$; in Tricholoma matsutake (S. Ito \& S. Imai) Singer, $10 \mathrm{mg} \mathrm{kg}^{-1} \mathrm{db}$; in Amanita exitialis Zhu L. Yang \& T.H. Li, $4.9 \mathrm{mg} \mathrm{kg}^{-1} \mathrm{db}$; and in Russula lepida Fr., current name R. rosea Pers., $4 \mathrm{mg} \mathrm{kg}^{-1} \mathrm{db}$ (Yin et al. 2012).

\section{Cs and Rb}

Cesium was determined only in a few samples in this study and $C$. cibarius from Poland and C. tubaeformis showed this element at 2.2 and $5.6 \mathrm{mg} \mathrm{kg}^{-1} \mathrm{db}$, and an order of magnitude smaller values were found in Yunnan's Cantharellus, which showed from 0.21 to $0.71 \mathrm{mg} \mathrm{kg}^{-1} \mathrm{db}$ (Table 2). Because of the nuclear weapon use and tests and the accidents in the Chernobyl nuclear power plant, the Cantharellus spp. and other mushrooms in Poland, while far less in Yunnan, can be contaminated with radioactive ${ }^{137} \mathrm{Cs}$ (Falandysz et al. 2016). Hence, ${ }^{137} \mathrm{Cs}$ in the Cantharellus spp. from Poland certainly contributed to total Cs as was measured by ICP-MS.

Also, rubidium was found at an order of magnitude greater content in C. cibarius and C. tubaeformis collected in Poland (200 to 550 and 320 to $540 \mathrm{mg} \mathrm{kg}^{-1} \mathrm{db}$ ), when related to $C$. cibarius and $C$. minor from Yunnan, which contained 61 and $64 \mathrm{mg} \mathrm{kg}^{-1} \mathrm{db}$. The smaller content of $\mathrm{Cs}$ and $\mathrm{Rb}$ in Cantharellus spp. in Yunnan could be related to the geochemical background condition of soils, which are highly weathered in Yunnan (He et al. 2004). 


\section{$\mathrm{Ba}$ and $\mathrm{Sr}$}

The Cantharellus spp. from Yunnan, when compared to Cantharellus spp. from Poland, could be considered as enriched in barium and strontium (Table 2). Barium in Yunnan was at 5.4 to $9.1 \mathrm{mg} \mathrm{kg}^{-1} \mathrm{db}$ and in Poland at $<2 \mathrm{mg} \mathrm{kg}^{-1} \mathrm{db}$ (median value) and strontium at 4.2 to $5.3 \mathrm{mg} \mathrm{kg}^{-1} \mathrm{db}$ and at $<2 \mathrm{mg} \mathrm{kg}^{-1} \mathrm{db}$. An exception was C. cibarius from the site in Jastrzębia Góra in the Baltic Sea coastal area in Poland, which contained $\mathrm{Sr}$ at $12 \mathrm{mg} \mathrm{kg}^{-1} \mathrm{db}$ (Table 2). Both Ba and Sr may be enriched in the polymetallic soils of Yunnan due to a geochemical anomaly (Fan 1991). This could have an impact on occurrence of $\mathrm{Ba}$ and $\mathrm{Sr}$ in mushrooms in Yunnan.

Data are lacking on efficiency of bioconcentration by mushrooms of $\mathrm{Ba}$ and $\mathrm{Sr}$ from soils poor in $\mathrm{Ca}$. Certain mushrooms, e.g., stinkhorns such as Phallus impudicus L. and Clathrus ruber P. micheli ex Pers., have much calcium, which is used to stabilize the gelatinous layer protecting the embryonal carpophore, and they also concentrate $\mathrm{Ba}$ and $\mathrm{Sr}$ (T. Stijve, personal information). Also, some slime molds, e.g., Fuligo septica (L.) Wiggers, can well accumulate $\mathrm{Ca}, \mathrm{Ba}$, and Sr (Setala and Nuorteva 1989; Stijve et al. 1999).

Barium at $14 \mathrm{mg} \mathrm{kg}^{-1} \mathrm{db}$ and strontium at $2.8 \mathrm{mg} \mathrm{kg}^{-1} \mathrm{db}$ were at elevated levels also in $C$. minor from Yunnan (Yin et al. 2012). Boletus species foraged in Yunnan also showed an elevated content of ${ }^{90} \mathrm{Sr}$ (and a very low amount of ${ }^{137} \mathrm{Cs}$ ) from radioactive fallout, when related to individuals foraged in Poland (Falandysz et al. 2016; Saniewski et al. 2016).

\section{Ni, V, and U}

Nickel was at similar contents in the Cantharellus mushrooms in Poland (range from 0.88 to $2.2 \mathrm{mg} \mathrm{kg}^{-1} \mathrm{db}$ ) and Yunnan (0.58 to $1.1 \mathrm{mg} \mathrm{kg}^{-1} \mathrm{db}$ ) (Table 2). C. cibarius foraged in several places in Poland when examined by ICP-OES showed Ni from $0.77 \pm 0.22$ to $2.0 \pm 0.6 \mathrm{mg} \mathrm{kg}^{-1} \mathrm{db}$ (Falandysz and Drewnowska 2015). Data on Ni in C. cibarius, C. minor, and C. tubaeformis obtained by ICP-MS (Table 2) confirmed that the content of this element in Cantharellus mushrooms rarely exceeds $2.0 \mathrm{mg} \mathrm{kg}^{-1} \mathrm{db}$, as was indicated by the ICP-OES analyses (Falandysz and Drewnowska 2015).

Vanadium was found at a greater content in C. cibarius and C. minor mushrooms in Yunnan (ranging from 0.63 to $0.88 \mathrm{mg} \mathrm{kg}^{-1} \mathrm{db}$ ) than in Poland (ranging from 0.035 to $0.25 \mathrm{mg} \mathrm{kg}^{-1} \mathrm{db}$ ) (Table 2). Vanadium is one of the metallic elements that are enriched in red and yellow soils of Yunnan (Fan 1991). C. cibarius sampled from the paleozolic graywacke bedrock in Western Bohemia contained vanadium at $0.21 \pm 0.04 \mathrm{mg} \mathrm{kg}^{-1} \mathrm{db}$ ( ̌̌anda and Kučera 2004), which is similar to the maximum value of $0.25 \mathrm{mg} \mathrm{kg}^{-1} \mathrm{db}$ determined in $C$. cibarius from a site in Poland in this study. The median value for mushrooms from Poland was at $0.11 \mathrm{mg} \mathrm{kg}^{-1} \mathrm{db}$ (Table 2).

Uranium was at 0.031 to $0.034 \mathrm{mg} \mathrm{kg}^{-1} \mathrm{db}$ in the Cantharellus mushrooms in Yunnan and at 0.0015 to $0.13 \mathrm{mg} \mathrm{kg}^{-1} \mathrm{db}$ in Poland (Table 2). Those values for Cantharellus mushrooms are close to the median value of $0.063 \mathrm{mg} \mathrm{kg}^{-1} \mathrm{db}$ and are within the range for uranium in ectomycorrhizal macro fungi growing in an unpolluted area (Kubrová and Borovička 2015).

\section{Ag, As, Cd, Pb, and Tl}

Silver in C. cibarius was at 0.075 to $0.54 \mathrm{mg} \mathrm{kg}^{-1} \mathrm{db}$, in C. minor at $1.0 \mathrm{mg} \mathrm{kg}^{-1} \mathrm{db}$, and in C. tubaeformis at 0.096 to $0.55 \mathrm{mg} \mathrm{kg}^{-1} \mathrm{db}$ (Table 2). Those values agree with what was noted in $C$. cibarius from numerous places in Poland and in Czech Republic, which contained $\mathrm{Ag}$ at $0.60 \pm 0.21 \mathrm{mg}$ $\mathrm{kg}^{-1} \mathrm{dm}$, from $0.050 \pm 0.017$ to $0.19 \pm 0.04 \mathrm{mg} \mathrm{kg}^{-1} \mathrm{dm}$, and at $0.17 \pm 0.04 \mathrm{mg} \mathrm{kg}^{-1} \mathrm{dm}$, when examined respectively by $\mathrm{F}$ AAS, ICP-OES, and neutron activation analysis (Falandysz and Drewnowska 2015; Falandysz et al. 1994; Řanda and Kučera 2004).

Arsenic in C. cibarius from Poland was at 0.066 to $0.21 \mathrm{mg} \mathrm{kg}^{-1} \mathrm{db}$ and in C. tubaeformis at 0.19 to $0.29 \mathrm{mg} \mathrm{kg}^{-1}$ $\mathrm{db}$, while mushrooms from Yunnan showed greater contents: $0.75 \mathrm{mg} \mathrm{kg}^{-1} \mathrm{db}$ in C. cibarius and $1.2 \mathrm{mg} \mathrm{kg}^{-1} \mathrm{db}$ in C. minor. Deposition of airborne As in forests in the northwestern part of Poland is low (Steinnes and Twardowska 2016). Mushrooms from the forested areas with geochemical anomaly in Poland can be richer in geogenic As when related to those foraged from a typical background areas. An example was mushroom Amanita fulva from the Lower Silesia forest in region of a geochemical anomaly in SW Poland having As at $0.78 \pm 0.05 \mathrm{mg} \mathrm{kg}^{-1} \mathrm{db}$ in caps and $1.3 \pm 0.1 \mathrm{mg} \mathrm{kg}^{-1} \mathrm{db}$ in stipes (Falandysz et al. 2017). Arsenic content was also low $\left(0.36 \pm 0.02 \mathrm{mg} \mathrm{kg}^{-1} \mathrm{db}\right)$ in $C$. cibarius from Western Bohemia (̌̌anda and Kučera 2004).

The laterite red earths and red earths and yellow earths of Yunnan are enriched in the metalloids As and Sb (Fan 1991). This could explain a somewhat elevated content of As in Cantharellus mushrooms in Yunnan in this study while levels were relatively low (Table 2).

Cadmium was relatively well studied in C. cibarius in Europe, while there is lack of comprehensive information on the occurrence of this heavy metal in material from Yunnan in China (Falandysz and Drewnowska 2015). Cadmium in portion is leaching out when $C$. cibarius is blanched (Unpublished; JF). This metallic element occurred at $1.6 \mathrm{mg} \mathrm{kg}^{-1} \mathrm{db}$ in $C$. cibarius from the Pieszków site in the Świętokrzyskie Mountains region, which could be considered as elevated compared to the range from 0.23 to $0.82 \mathrm{mg} \mathrm{kg}^{-1}$ $\mathrm{db}$ for other places in Poland in this study (Table 2). The median value of $\mathrm{Cd}$ in $C$. cibarius for a range of sites in 
Poland was determined in an earlier study at 0.15 to $0.36 \mathrm{mg} \mathrm{kg}^{-1} \mathrm{db}$ (Falandysz and Drewnowska 2015). The Świętokrzyskie Mountains area is enriched in some metal ores and also with a long history of some metallurgic industrial activities in certain sites (Gałuszka et al. 2015). Hence, as it was in the case of copper, an overriding source of $\mathrm{Cd}$ in C. cibarius from the Świętokrzyskie Mountains region can be geogenic than anthropogenic $\mathrm{Cd}$.

Cadmium in C. cibarius in Yunnan was at $0.58 \mathrm{mg} \mathrm{kg}^{-1} \mathrm{db}$ and somewhat higher in $C$. minor, i.e., at $2.5 \mathrm{mg} \mathrm{kg}^{-1} \mathrm{db}$. In a sample of $C$. minor from the northern region of Yunnan, Yin et al. (2012) found this element at $1.6 \mathrm{mg} \mathrm{kg}^{-1} \mathrm{db} . \mathrm{Cd}$ in C. tubaeformis was similar to its content in $C$. cibarius and from 0.44 to $0.75 \mathrm{mg} \mathrm{kg}^{-1} \mathrm{db}$. Cadmium, in a recent study from NW Spain, was found in the gills of $C$. cibarius at $0.43 \pm 0.19 \mathrm{mg} \mathrm{kg}^{-1} \mathrm{db}(0.17-0.71 ; n=13)$ and in the main part of fruiting bodies at $0.25 \pm 0.12 \mathrm{mg} \mathrm{kg}^{-1} \mathrm{db}(0.31-1.2)$ (Melgar et al. 2016).

Lead in C. cibarius and $C$. tubaeformis from Poland was respectively at range $0.17-0.66$ and $0.64-0.72 \mathrm{mg} \mathrm{kg}^{-1} \mathrm{db}$ and similar to $C$. cibarius in Yunnan, i.e., at $1.1 \mathrm{mg} \mathrm{kg}^{-1} \mathrm{db}$. Pollution with the airborne lead of the forested areas in Poland outside of large local emitters was considered low in the past (Andersen et al. 1994) and recently (Steinnes and Twardowska 2016). In light of the data for $C$. cibarius, C. minor from Yunnan with lead at $4.4 \mathrm{mg} \mathrm{kg}^{-1} \mathrm{db}$ could be considered as contaminated. The species $C$. minor from the northern region of Yunnan showed lead at $2.6 \mathrm{mg} \mathrm{kg}^{-1} \mathrm{db}$ (Yin et al. 2012).

There is no earlier information on the occurrence of thallium in Cantharellus mushrooms from Poland or Yunnan. In this study, $C$. cibarius from the Osiek site in the Tuchola Pinewoods contained thallium at $2.2 \mathrm{mg} \mathrm{kg}^{-1} \mathrm{db}$, which is an elevated level when compared to $C$. cibarius sampled elsewhere in Poland (range 0.033 to $0.35 \mathrm{mg} \mathrm{kg}^{-1} \mathrm{db}$ ), and also to C. tubaeformis (range from 0.066 to $0.094 \mathrm{mg} \mathrm{kg}^{-1} \mathrm{db}$ ) (Table 2). A reason of an elevated content of $\mathrm{Tl}$ in C. cibarius from the Tuchola Pinewoods is unknown since no data on its content and origin in soil there can be available. Data on thallium in forest soil of Poland are lacking, while concentrations of $\mathrm{Tl}$ extracted by EDTA in soils of other types were low, i.e., in range $0.1-0.4 \mathrm{mg} \mathrm{kg}^{-1}$, and elevated in soils from a site close to the zinc ore mine waste dumping site (Łukaszewicz and Zembrzuski 1992).

Several species of mushrooms sampled in Poland when examined by high-resolution ICP-MS showed thallium at $<0.1 \mathrm{mg} \mathrm{kg}^{-1} \mathrm{db}$ (Falandysz et al. 2001).

\section{Multivariate analysis}

A multivariate approach and applying the principal component analysis (PCA) (Chudzińska and Barałkiewicz 2010; Wyrzykowska et al. 2001) has been used to examine the correlation matrix from a possible $17 \times 15$ data matrix $(17$ elements sequestered in fruiting bodies by $C$. cibarius $(\mathrm{CC})$, C. minor (CM), and C. tubaeformis (CT) from 15 places) but without cesium that was determined only in six samples), and results are presented in Table 3 and Fig. 2. All data were standardized to bring values to compatible units from a distribution with a mean of 0 and a standard deviation of 1 . In choosing the number of components, the Kaiser criterion (factors with eigenvalues greater than 1) and scree test were used. Varimax normalized rotation was used in order to maximize the variances of normalized factor loadings across variables for each factor. Loadings values of $>0.75$ are considered strong, between 0.75 and 0.5 moderate, and 0.5 and 0.3 weak based on their absolute values. In this study, only component loadings $\geq 0.55$ were taken for interpretation. The PCA examination of data (absolute concentration values and sampling places) revealed that $85 \%$ of information regarding the mineral compositional variability in mushroom samples for all examined sites could be described by four components.

The component loadings showed that the PC1 explained $34 \%$ of the total variance and loaded on the positively and negatively (for $\mathrm{Rb}$ ) correlated variables, describing significant association between $\mathrm{V}$, As, $\mathrm{Ag}, \mathrm{Cd}, \mathrm{Pb}, \mathrm{Ba}$, and $\mathrm{U}$ in chanterelles independently of the species and place. The PC2 was loaded primarily by positively correlated $\mathrm{Cr}$ and negatively correlated $\mathrm{Cu}$ and $\mathrm{Tl}$ and accounted for $18 \%$ of the total variance. The PC3 was correlated (negatively) with Mn and Rb

Table 3 Factor loadings (varimax normalized rotation)

\begin{tabular}{lllll}
\hline Eigenvalues & 5.7 & 3.1 & 3.1 & 2.5 \\
\hline Total variance (\%) & 34 & 18 & 18 & 15 \\
Cumulative (\%) & 34 & 52 & 70 & 85 \\
Variables & $\mathrm{PC} 1$ & $\mathrm{PC} 2$ & $\mathrm{PC} 3$ & $\mathrm{PC} 4$ \\
$\mathrm{Li}$ & 0.19 & 0.47 & $0.75^{\#}$ & 0.26 \\
$\mathrm{~V}$ & 0.83 & 0.49 & 0.25 & 0.06 \\
$\mathrm{Cr}$ & 0.53 & 0.55 & 0.49 & 0.21 \\
$\mathrm{Mn}$ & -0.37 & 0.13 & -0.81 & 0.28 \\
$\mathrm{Co}$ & 0.08 & 0.05 & -0.21 & 0.90 \\
$\mathrm{Ni}$ & -0.35 & 0.04 & -0.22 & 0.87 \\
$\mathrm{Cu}$ & -0.25 & -0.79 & 0.04 & 0.14 \\
$\mathrm{Zn}$ & 0.10 & -0.28 & 0.21 & 0.77 \\
$\mathrm{As}$ & 0.87 & 0.40 & 0.20 & -0.10 \\
$\mathrm{Rb}$ & -0.57 & -0.28 & -0.59 & 0.33 \\
$\mathrm{Sr}$ & 0.07 & 0.14 & 0.83 & -0.13 \\
$\mathrm{Ag}$ & 0.92 & -0.13 & 0.05 & -0.06 \\
$\mathrm{Cd}$ & 0.94 & -0.22 & 0.03 & -0.01 \\
$\mathrm{Ba}$ & 0.57 & 0.53 & 0.39 & 0.02 \\
$\mathrm{~Pb}$ & 0.90 & 0.26 & 0.077 & -0.04 \\
$\mathrm{Tl}$ & 0.13 & -0.80 & -0.21 & 0.11 \\
$\mathrm{U}$ & 0.66 & 0.55 & 0.38 & 0.16 \\
\hline & & & &
\end{tabular}

\# strong interreletion (in Italics) 
Fig. 2 Principal component analysis of the trace metallic elements and arsenic in Cantharellus mushrooms and places of collection (a PC1/PC2; b PC3/PC4). Associations among the places are shown on $\mathrm{PC} 1$ and PC2 (a) and PC3 and PC4 with Varimax unrotated matrixes
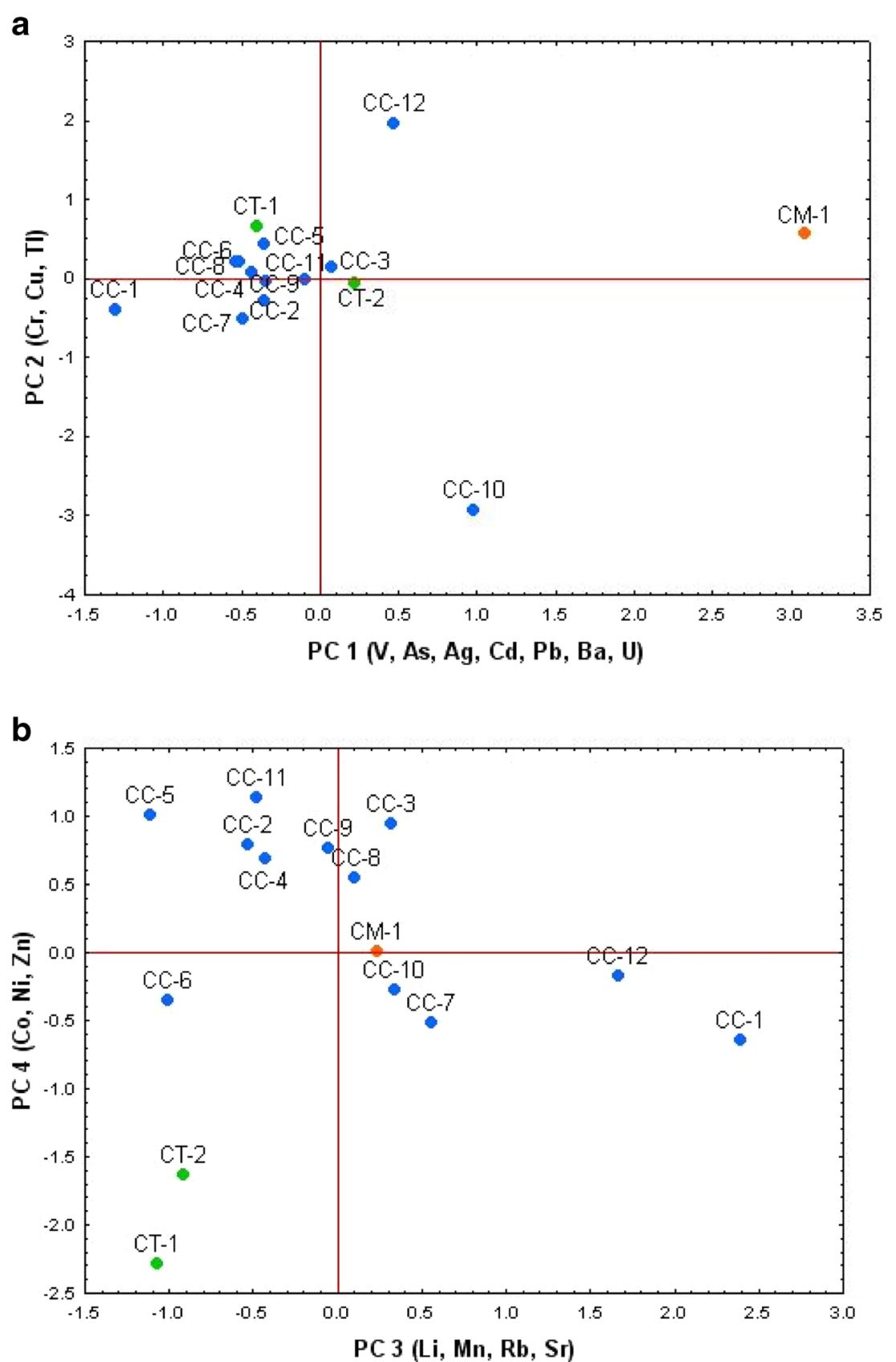

and (positively) with $\mathrm{Li}$ and $\mathrm{Sr}$ and explained $18 \%$ of the total variance, while PC4, which positively correlated with $\mathrm{Co}, \mathrm{Ni}$, and $\mathrm{Zn}$, accounted for $15 \%$ of the total variance.

A projection of datasets on the factor plane allowed the visualization of the relationship between the trace element contents of the samples and the sampling places (Fig. 2). Projection of data on the PC1 and PC2 plane separated a sample of $C$. minor (CM-1) from China, which indicated the highest contents of $\mathrm{V}$, As, $\mathrm{Ag}, \mathrm{Cd}, \mathrm{Pb}, \mathrm{Ba}$, and $\mathrm{U}$ while lowest of $\mathrm{Rb}$, while $C$. cibarius (CC-1) from the coastal region of the Jastrzębia Góra site in the Baltic Sea costal area in Poland was lowest in those elements except of Rb (Fig. 2a). Next,
C. cibarius (CC-12) from China separated by PC2 had the highest content of $\mathrm{Cr}$ with the lowest content of $\mathrm{Cu}$ and $\mathrm{Tl}$, while C. cibarius (CC-10) from the Piekoszów site in the Świętokrzyskie Mountains with a highest content of $\mathrm{Cu}$ and elevated $\mathrm{Tl}$ was relatively poor in $\mathrm{Cr}$ (Fig. 2a). Projection of data on the PC3 and PC4 plane (Fig. 2b) separated C. cibarius (CC-12) from China and Jastrzębia Góra (CC-1), because of the higher content of $\mathrm{Li}$ and $\mathrm{Sr}$ and lower of $\mathrm{Mn}$ and $\mathrm{Rb}$. Also, C. tubaeformis (CT-1 and CT-2) from both sites separates from other collections (negative correlation), because of lower contents of correlated $\mathrm{Co}, \mathrm{Ni}$, and $\mathrm{Zn}$ in its fruiting bodies, while a positive tendency could be observed between those 
elements in C. cibarius from three sites in Poland (CC-5 for Tuchola Pinewoods, CC-11 for Głogów Małopolski, and CC3 for Kościerskie forests).

Since total concentrations of the elements were determined, the associations found can be largely explained by considering that the mineral content of mushrooms depends on the (i) geochemical composition of soil bedrock - as was observed for lithophile elements such as $\mathrm{As}, \mathrm{Ba}, \mathrm{Cr}, \mathrm{Li}, \mathrm{Sr}, \mathrm{V}$, and $\mathrm{U}$ which were relatively abundant in chanterelles but are known as abundant in red and yellow earths of Yunnan or were lower (Mn, Rb) in mushrooms from Yunnan, (ii) chalcophilicity of certain elements (Ag, $\mathrm{As}, \mathrm{Cd}, \mathrm{Pb}$ ), and (iii) essentiality concentrations - adequate supplementation and sometimes deficiency or excess $(\mathrm{Cu}, \mathrm{Co}, \mathrm{Mn}, \mathrm{Ni}, \mathrm{Zn})$.

\section{Conclusions}

This study filled some information gaps on the mineral constituents of $C$. cibarius foraged in Poland and in Yunnan, China. Provided were for first time and discussed data on As, Li, V, Tl, and $\mathrm{U}$ in chanterelles from Poland and on $\mathrm{Ba}$, $\mathrm{Co}, \mathrm{Cr}, \mathrm{Ni}, \mathrm{Rb}$, and $\mathrm{Sr}$ in chanterelles from China. The results obtained suggest a strong influence of the collection site on the occurrence of As, $\mathrm{Ba}, \mathrm{Cr}, \mathrm{Li}, \mathrm{Mn}, \mathrm{Pb}, \mathrm{Rb}, \mathrm{Sr}, \mathrm{U}$, and $\mathrm{V}$ in fruit bodies. These elements were found at higher values in Cantharellus mushrooms from polymetallic soils of Yunnan in China, but lower values were measured for $\mathrm{Cs}, \mathrm{Mn}$, and $\mathrm{Rb}$, when compared to fruit bodies from Poland.

Acknowledgements This study in part was financially supported to by the National Science Center of Poland under call PRELUDIUM (project no. DEC-2012/05/N/NZ9/01561).

Open Access This article is distributed under the terms of the Creative Commons Attribution 4.0 International License (http:// creativecommons.org/licenses/by/4.0/), which permits unrestricted use, distribution, and reproduction in any medium, provided you give appropriate credit to the original author(s) and the source, provide a link to the Creative Commons license, and indicate if changes were made.

\section{References}

Aloupi M, Koutrotsios G, Koulousaris M, Kalogeropoulos N (2011) Trace metal contents in wild edible mushrooms growing on serpentine and volcanic soils on the island of Lesvos, Greece. Ecotoxicol Environ Saf 78:184-194

Andersen S, Ødegård S, Vogt RD, Seip HM (1994) Background levels of heavy metals in Polish forest soils. Ecol Eng 3:245-253

Barret CL, Beresford NA, Self PL, Howard BJ, Frankland JC, Fulker MJ, Dodd BA, Marriott IVR (1999) Radiocaesium activity concentrations in the fruit-bodies of macrofungi in Great Britain and an assessment of dietary intake habits. Sci Total Environ 231:67-83

Chudzińska M, Barałkiewicz D (2010) Estimation of honey authenticity by multielements characteristics using inductively coupled plasma- mass spectrometry (ICP-MS) combined with chemometrics. Food Chem Toxicol 48:284-290

Dimitrijevic MV, Mitic VD, Cvetkovic JS, Stankov Jovanovic VP, Mutic JJ, Nikolic Mandic SD (2016) Update on element content profiles in eleven wild edible mushrooms from family Boletaceae. Eur Food Res Technol 242:1-10

Drewnowska M, Falandysz J (2015) Investigation on mineral composition and accumulation by popular edible mushroom common chanterelle (Cantharellus cibarius). Ecotoxicol Environ Saf 113:9-17

Falandysz J, Drewnowska M (2015) Macro and trace elements in common Chanterelle (Cantharellus cibarius) mushroom from the European background areas in Poland: composition, accumulation, dietary exposure and data review for species. J Environ Sci Health Part B 50:374-387

Falandysz J, Bona H, Danisiewicz D (1994) Silver content of wild-grown mushrooms from northern Poland. Zeitschr Lebensm Unters Forsch 199:222-224

Falandysz J, Szymczyk K, Ichihashi H, Bielawski L, Gucia M, Frankowska A, Yamasaki S (2001) ICP/MS and ICP/AES elemental analysis (38 elements) of edible wild mushrooms growing in Poland. Food Addit Contam 18:503-513

Falandysz J, Drewnowska M, Jarzyńska G, Zhang D, Zhang Y, Wang J (2012a) Mineral constituents in common chanterelles and soils collected from a high mountain and lowland sites in Poland. J Mt Sci 9: $697-705$

Falandysz J, Widzicka E, Kojta AK, Jarzyńska G, Drewnowska M, Dryżałowska A, Danisiewicz-Czupryńska D, Lenz E, Nnorom IC (2012b) Mercury in common chanterelles mushrooms: Cantharellus spp. update. Food Chem 133:842-850

Falandysz J, Zalewska T, Apanel A, Drewnowska M, Kluza K (2016) Determination of activity concentration of ${ }^{137} \mathrm{Cs}$ and ${ }^{40} \mathrm{~K}$ in some chanterelle mushrooms in Poland and China. Environ Sci Poll Res 23:20039-20048

Falandysz J, Drewnowska M, Chudzińska M, Barałkiewicz D (2017) Accumulation and distribution of metallic elements and metalloids in edible Amanita fulva mushrooms. Ecotoxicol Environ Saf 137: 265-271

Fan C (1991) A study on the origin of ore-forming materials in the antimony and mercury multiple-metal ore zone at Weisha, Yunnan Province, China (in Chinese). Geochemica 12:399-405

Gałuszka A, Migaszewski ZM, Dołegowska S, Michalik A, DuczmalCzernikiewicz A (2015) Geochemical background of potentially toxic trace elements in soils of the historic copper mining area: a case study from Miedzianka Mt., Holy Cross Mountains, southcentral Poland. Environ Earth Sci 74:4589-4605

Gąsecka M, Rzymski P, Mleczek M, Siwulski M, Budzyńska S, Magdziak Z, Niedzielski P, Sobieralski K (2017) The relationship between metal composition, phenolic acid and flavonoid content in Imleria badia from non-polluted and polluted areas. J Environ Sci Health Part B 52:171-177

He Z, Zhang M, Wilson MJ (2004) Distribution and classification of red soils in China. In: Wilson MJ (ed) The red soils of China. Netherlands, Springer, pp 29-33

Jorhem L, Sundström B (1995) Levels of some trace elements in edible fungi. Zeitschr Lebensm Unters Forsch 201:311-316

Kojta AK, Falandysz J (2016) Soil-to-mushroom transfer and diversity in total mercury content in two edible Laccaria mushrooms. Environ Earth Sci 75:1264

Kojta AK, Wang Y, Zhang J, Li T, Saba M, Falandysz J (2015) Mercury contamination of fungi genus Xerocomus in the Yunnan Province in China and the region of Europe. J Environ Sci Health Part A 50: $1342-1350$

Kubrová J, Borovička J (2015) Do macrofungi accumulate uranium? In uranium - past and future challenges. B. J. Merlel, A. Arab (eds) Proceedings of the 7th International Conference on Uranium Mining and Hydrogeology. Springer International Publishing pp. 369-376 
Łukaszewicz Z, Zembrzuski W (1992) Determination of thallium in soils by flow-injection-differential pulse anode stripping voltammetry. Talanta 39:221-227

Mędyk M, Chudzińska M, Barałkiewicz D, Falandysz J (2017) Specific accumulation of cadmium and other trace elements in Sarcodon imbricatus using ICP-MS with a chemometric approach. J Environ Sci Health Part B 52. doi.10.1080/03601234.2017.1283145

Melgar MJ, Alonso J, García MA (2016) Cadmium in edible mushrooms from NW Spain: Bioconcentration factors and consumer health implications. Food Chem Toxicol 88:13-20

Mleczek M, Siwulski M, Mikołajczak P, Gąsecka M, Rissmann I, Goliński P, Sobieralski K (2015) Differences in Cu content in selected mushroom species growing in the same unpolluted areas in Poland. J Environ Sci Health Part B 50:659-666

Mleczek M, Niedzielski P, Kalač P, Budka M, Siwulski M, Gąsecka M, Rzymski P, Magdziak Z, Sobieralski K (2016) Multielemental analysis of 20 mushroom species growing near a heavily trafficked road in Poland. Environ Sci Poll Res 23:16280-16295

Mleczek M, Siwulski M, Rzymski P, Niedzielski P, Gąsecka M, Jasińska A, Budzyńska S, Budka A (2017) Multielemental analysis of Lentinula edodes mushrooms available in trade. J Environ Sci Health Part B 52:196-205

Nearing MM, Koch I, Reimer KJ (2014) Arsenic speciation in edible mushrooms. Environ Sci Technol 48:14203-14210

Nygård T, Steinnes E, Røyset O (2012) Distribution of 32 elements in organic surface soils: contributions from atmospheric transport of pollutants and natural sources. Water Air Soil Pollut 223:699-713

Řanda Z, Kučera J (2004) Trace elements in higher fungi (mushrooms) determined by activation analysis. J Radioanal Nucl Chem 259:99107

Saniewski M, Zalewska T, Krasińska G, Szylke N, Wang Y, Falandysz J (2016) ${ }^{90} \mathrm{Sr}$ in King Bolete Boletus edulis and certain other mushrooms consumed in Europe and China. Sci Total Environ 543:287294

Setala A, Nuorteva P (1989) High metal contents found in Fuligo septica (L.) Wiggers and some other slime molds (Myxomycetes). Karstenia 29:37-44
Stefanović V, Trifković J, Mutić J, Tešić Ž (2016a) Metal accumulation capacity of parasol mushroom (Macrolepiota procera) from Rasina region (Serbia). Environ Sci Poll Res 23:13178-13190

Stefanović V, Trifković J, Djurdjić S, Vukojević V, Tešić Ž, Mutić J (2016b) Study of silver, selenium and arsenic concentration in wild edible mushroom Macrolepiota procera, health benefit and risk. Environ Sci Poll Res 23:22084-22098

Steinnes E, Friedland AJ (2006) Metal contamination of natural surface soils from long-range atmospheric transport: existing and missing knowledge. Env Rev 14:169-186

Steinnes E, Twardowska I (2016) Poland as a source region of heavy metal deposition in Norway as assessed by analysis of peat cores. Abstract book of the 18th international conference on heavy metals in the environment, 12 to 15 September 2016. Ghent, Belgium, pp 509-510

Stijve T, Andrey D, Goessler W (1999) Accumulation of various metals by Fuligo septica L. Wiggers and by some other slime molds (Myxomycetes). Australasian Mycologist 18:23-26

Tel G, Çavdar H, Deveci E, Öztürk M, Duru ME, Turkoğlub A (2014) Minerals and metals in mushroom species in Anatolia. Food Addit Contam B 7:226-231

Vetter J (2005) Lithium content of some common edible wild-growing mushrooms. Food Chem 90:31-37

Wyrzykowska B, Szymczyk K, Ichihashi H, Falandysz J, Skwarzec B, Yamasaki S (2001) Application of ICP sector field MS and principal component analysis for studying interdependences among 23 trace elements in Polish beers. J Agric Food Chem 49:3425-3431

Yin L-L, Shi G-Q, Tian Q, Shen T, Ji Y-Q, Zeng G (2012) Determination of the metals by ICP-MS in wild mushrooms from Yunnan, China. J Food Sci 77:151-155

Zhang D, Frankowska A, Jarzyńska G, Kojta AK, Drewnowska M, Wydmańska D, Bielawski L, Wang J, Falandysz J (2010) Metals of King Bolete (Boletus edulis) collected at the same site over two years. African J Agric Res 5:3050-3055 